\title{
PENERAPAN PROMOSI KESEHATAN (PKRS) DI RUMAH SAKIT ISLAM FATIMAH BANYUWANGI
}

\section{Implementation of Health Promotion in Fatimah Islamic Hospital Banyuwangi}

\author{
1Chintya Devi, 2 Reynaldy Bimatara, ${ }^{3}$ Ayu Fitri Lestari, ${ }^{4}$ Jayanti Dian Eka Sari \\ ${ }^{1234}$ Departemen Promosi Kesehatan dan Ilmu Perilaku, Program Studi Kesehatan \\ Masyarakat, Fakultas Kesehatan Masyarakat PSDKU Universitas Airlangga, Banyuwangi \\ Email : chintya.devi-2015@fkm.unair.ac.id
}

\begin{abstract}
Health providers in Indonesia have an obligation to realize the improvement of health status through the national health system. The effort that must be done by the hospital in realizing these goal is the improvement of other services that is preventive and promotive. Therefore, Indonesia has implemented the health improvement by establishing a committee of Public Health Extension Workers which was changed in 2003 into Hospital Health Promotion. Health promotion is conducted in hospitals in order to develop the understanding of patients, families and visitors of the hospital with health problems and prevention efforts. Fatimah Islamic Hospital has implemented health promotion in hospitals in improving the quality of complete health services. This study aims to determine the implementation of health promotion that has been done by RSI Fatimah in Banyuwangi. The method used is interview and observation. Interviews were conducted to the PKRS team using an interview guide. While the observations made using instruments made based on references related theory of health promotion standards in hospitals. Based on the research results, health promotion conducted at RSI Fatimah as a whole has fulfilled the requirements of laws. Starting from the policy until the implementation is well arranged and directed. The division of PKRS officers consists of various fields that facilitate dissemination of health promotion information. In almost every service there is visual information such as leaflets, posters and information boards. Fatimah hospital is also active in providing counseling to patients, patient families and other health workers in an effort to increase knowledge on certain health problems, as well as spiritual guidance to inpatients. The fulfillment of health promotion needs in general has been well implemented, but at the point of providing information to the surrounding community isn't intense and hasn't formed a specific health group for community empowerment.
\end{abstract}

Keyword : implementation, health promotion in hospital

\begin{abstract}
Abstrak
Penyedia layanan kesehatan di Indonesia mempunyai kewajiban mewujudkan derajat kesehatan melalui sistem kesehatan nasional sebagai kepanjangan rencana kesehatan di Indonesia. Upaya yang harus dilakukan rumah sakit sebagai salah satu penyedia layanan kesehatan dalam mewujudkan cita-cita tersebut adalah peningkatan pelayanan lainnya yaitu secara preventif dan promotif. Oleh karena itu, Indonesia telah melaksanakan peningkatan kesehatan tersebut dengan mendirikan panitia Penyuluh Kesehatan 1234 Chintya Devi, Reynaldy Bimatara, Ayu Fitri Lestari, Jayanti Dian Eka Sari adalah Departemen Promosi Kesehatan dan Ilmu Perilaku, Program Studi Kesehatan Masyarakat, Fakultas Kesehatan Masyarakat PSDKU Universitas Airlangga, Banyuwangi
\end{abstract}


Masyarakat di Rumah Sakit (PKMRS) yang kemudian dirubah pada tahun 2003 menjadi Promosi Kesehatan Rumah Sakit (PKRS). Promosi kesehatan dilakukan di rumah sakit dalam rangka mengembangkan pengertian dari pasien, keluarga dan pengunjung rumah sakit tekait dengan masalah kesehatan serta upaya pencegahannya. Rumah Sakit Islam (RSI) Fatimah merupakan penyedia layanan kesehatan yang telah menerapkan promosi kesehatan di rumah sakit dalam meningkatkan mutu pelayanan kesehatan yang lengkap dan paripurna. Penelitian ini bertujuan untuk mengetahui pelaksanaan promosi kesehatan yang telah dilakukan oleh RSI Fatimah di Banyuwangi. Metode yang digunakan adalah wawancara dan observasi. Wawancara dilakukan kepada tim PKRS dengan menggunakan panduan wawancara. Sementara observasi yang dilakukan menggunakan instrumen yang dibuat berdasarkan rujukan teori terkait standar promosi kesehatan di rumah sakit. Berdasarkan hasil penelitian, promosi kesehatan yang dilakukan di RSI Fatimah secara keseluruhan telah memenuhi persyaratan undang-undang. Mulai dari kebijakan hingga pelaksanaan disusun dengan baik dan terarah. Pembagian petugas PKRS terdiri dari berbagai bidang yang mempermudah diseminasi informasi promosi kesehatan. Hampir di setiap pelayanan terdapat pemberian informasi secara visual seperti leaflet, poster maupun papan informasi. Rumah sakit Fatimah juga aktif dalam memberikan penyuluhan kepada pasien, keluarga pasien dan petugas kesehatan lain dalam upaya peningkatan pengetahuan terhadap masalah kesehatan tertentu, serta bimbingan rohani kepada pasien rawat inap. Pemenuhan kebutuhan promosi kesehatan secara umum telah dilaksanakan dengan baik, akan tetapi pada poin pemberian informasi kepada masyarakat sekitar terlihat tidak intens dan belum membentuk kelompok kesehatan tertentu guna pemberdayaan masyarakat.

Kata Kunci : pelaksanaan, promosi kesehatan rumah sakit

\section{PENDAHULUAN}

Penyedia layanan kesehatan di Indonesia mempunyai kewajiban mewujudkan derajat kesehatan melalui sistem kesehatan nasional sebagai kepanjangan rencana kesehatan di Indonesia. Menurut Departemen Kesehatan RI (2009), upaya kesehatan dalam mewujudkan derajat yang setinggi-tingginya perlu diselenggarakan melalui cara peningkatan pencegahan, pengobatan, dan pemulihan.

Tentu dalam melaksanakan tindakan kuratif dan rehabilitatif, rumah sakit menjadi rujukan utama setelah layanan primer tidak mampu mengatasi permasalahannya, akan tetapi dengan niat mewujudkan cita-cita kesehatan yang tertuang pada Undang-Undang
Nomor 36 Tahun 2009 Tentang Kesehatan dalam pasal tiga menyatakan bahwa pembangunan kesehatan bertujuan meningkatkan kesadaran, kemauan, dan kemampuan hidup sehat bagi setiap orang agar terwujud derajat kesehatan yang setinggi-tingginya. Mewujudkan cita-cita tersebut maka peningkatan pelayanan lainnya yaitu secara preventif dan promotif juga harus dilakukan oleh rumah sakit. Oleh karena itu Indonesia telah melaksanakan peningkatan kesehatan tersebut dengan mendirikan panitia Penyuluh Kesehatan Masyarakat di Rumah Sakit (PKMRS) yang kemudian dirubah pada tahun 2003 menjadi Promosi Kesehatan Rumah Sakit (PKRS) (HPH Organization, 2001).

Manajemen kesehatan harus dikembangkan pada setiap lini hirarki 
pelayanan kesehatan dari menteri kesehatan, dinas kesehatan hingga pelaksana teknis seperti puskesmas dan rumah sakit. Upaya membentuk rencana kerja tertentu puskesmas dan rumah sakit harus bersinergi dengan sistem kesehatan nasional yang bertanggung jawab melaksanakan sistem administrasi umum (public administration), oleh karena itu organisasi kesehatan lebih mementingkan pencapaian kesejahteraan masyarakat umum (Bastian, 2014). Konferensi PKRS dunia ke 9 (2001), menyatakan bahwa PKRS harus memikirkan kepada kebijakan nasional yang mendorong kepada faktorfaktor penentu kebijakan, PKRS memikirkan kembali peran mereka terhadap pemberian pelayanan terpadu kepada perorangan maupun masyarakat yang mengacu pada pembangunan kesehatan berkelanjutan. Rumah sakit juga turut turun tangan kepada masyarakat rentan dan memberikan efek samping yang positif, hal ini diwujudkan melalui implementasi program promosi kesehatan dalam praktek klinis.

Menurut Peraturan Menteri Kesehatan Republik Indonesia Nomor 004 Tahun 2012 Tentang Petunjuk Teknis Promosi Kesehatan Rumah Sakit, rumah sakit merupakan fasilitas pelayanan kesehatan yang memberikan pelayanan kesehatan perorangan secara paripurna meliputi promotif, preventif, kuratif dan rehabilitatif. Promosi kesehatan dilakukan di rumah sakit dalam rangka mengembangkan pengertian dari pasien, keluarga dan pengunjung rumah sakit tekait dengan masalah kesehatan serta upaya pencegahannya. Promosi kesehatan berupaya untuk meningkatkan kesadaran serta minat pasien, keluarga dan pengunjung rumah sakit serta berperan aktif dalam usaha penyembuhan dan pencegahan penyakit (Kemenkes RI, 2012).

Promosi kesehatan secara umum adalah memampukan individu maupun masyarakat supaya meningkat kemampuan diri dalam peningkatan derajat kesehatan. WHO telah merumuskan suatu bentuk definisi mengenai promosi kesehatan, "Promosi kesehatan adalah proses yang memungkinkan orang untuk meningkatkan kontrol, dan meningkatkan, kesehatan mereka. Untuk mencapai kesejahteraan yang lengkap fisik, mental, dan sosial, kesejahteraan, individu atau kelompok harus dapat mengidentifikasi dan mewujudkan aspirasi, untuk memenuhi kebutuhan, dan untuk mengubah atau mengatasi lingkungan" (WHO, 1986).

Menurut Notoatmojo (2007), promosi kesehatan memiliki 4 ruang lingkup, ruang lingkup tesebut, antara lain tingkat promotif, preventif, kuratif, dan rehabilitatif. Keempat ruang lingkup ini memiliki target sasaran masingmasing dari kelompok sehat hingga kelompok sakit untuk memaksimalkan pemulihan atau kemampuan tinggal. Rumah sakit dapat memenuhi keempat lingkup untuk menunjang kesembuhan pasien serta menjaga keluarga pasien dan masyarakat tetap sehat. Ottawa Charter dalam Notoatmojo (2007), mendorong pemerintah dan organisasi kesehatan lain dalam pelaksanaan promosi kesehatan melalui 5 strategi promosi kesehatan yaitu Health Public Policy, Supportive Environment, Reorient Health Services, Personal Skill, dan Community Action, yang jika dalam bahasa Indonesia yaitu kebijakan berwawasan kesehatan, lingkungan yang mendukung, reorientasi pelayanan kesehatan, ketrampilan individu, dan gerakan masyarakat. 
Rumah Sakit Islam Fatimah (RSI Fatimah) saat ini telah menerapkan promosi kesehatan di rumah sakit dalam meningkatkan mutu pelayanan kesehatan yang lengkap dan paripurna. Visi RSI Fatimah ini adalah menjadi rumah sakit dengan pelayanan prima dan sebagai sarana dakwah. Upaya yang dilakukan untuk mewujudkan visi tersebut adalah mewujudkan pelayanan kesehatan yang bermutu, meningkatkan kesejahteraan sumber daya manusia, dan menjadikan rumah sakit sebagai organisasi yang efektif dan efisien. Upaya untuk mewujudkan hal tersebut RSI Fatimah telah mendirikan tim pelaksana PKRS yang bekerja bersama tim humas dan marketing. Yang dilaksanakan di segala lingkup. Tim tersebut melaksanakan tugas sesuai Permenkes No, 004 Tahun 2012, melaksanakan promosi kesehatan di dalam gedung maupun di luar gedung dengan target pasien, keluarga pasien, masyarakat sekitar, hingga petugas kesehatan di RSI Fatimah.

Berdasarkan pemikiran dan latar belakang tersebut, peneliti merasa bahwa kegiatan penilaian promosi kesehatan yang dilaksanakan oleh tim PKRS penting untuk melihat pelaksanaan strategi promosi kesehatan yang dilakukan oleh RSI Fatimah. Peningkatan mutu dan perkembangan strategi promosi kesehatan perlu dilakukan kepada masyarakat RSI Fatimah.

\section{METODE}

Penelitian ini adalah penelitian deskriptif - kualitatif yang dilakukan untuk mendeskripsikan pelaksanaan promosi kesehatan rumah sakit di Rumah Sakit Islam (RSI) Fatimah Banyuwangi. Waktu pelaksanaan penelitian yaitu pada April Mei 2018. Metode yang digunakan dalam pengambilan data mengenai pelaksanaan promosi kesehatan di Rumah Sakit Fatimah terdiri dari observasi dan wawancara mendalam (indepth interview). Observasi dilakukan dengan menggunakan panduan observasi berupa instrumen. Instrumen yang dibuat terdiri dari beberapa unit penilaian yang berdasarkan rujukan teori PKRS. Instrumen observasi yang dibuat mengacu pada beberapa rujukan teori terkait dengan standar pelaksanaan promosi kesehatan rumah sakit. Peraturan tersebut diantaranya adalah Peraturan Menteri Kesehatan Nomor 04 Tahun 2012 Tentang Petunjuk Teknis Promosi Kesehatan Rumah Sakit yang terdiri dari dua komponen penilaian, yaitu promosi kesehatan di dalam gedung dan di luar gedung, serta rujukan lainnya dari Pusat Promosi Kesehatan, Kementrian Kesehatan RI Tahun 2013, dan Kementrian Kesehatan RI Tahun 2011 Tentang Standar PKRS (Promosi Kesehatan Rumah Sakit). Selain itu, instrumen ini juga digunakan untuk melihat keadaan dan keaktifan dari komponen-komponen yang ada. Tidak hanya melalui observasi, wawancara mendalam juga dilakukan untuk mengambil data. Wawancara dilakukan untuk menggali informasi lebih dalam terkait dengan pelaksanaan promosi kesehatan yang diajukan kepada salah satu perwakilan dari tim PKRS. Pertanyaan yang diajukan kepada informan telah ditentukan terlebih dahulu sesuai dengan tujuan penelitian dan dituliskan dalam pedoman wawancara mendalam (indepth interview). Hasil dari penelitian ini berupa data primer dan data sekunder yang didapat dari kedua metode pengambilan data yang dilakukan. 


\section{HASIL DAN PEMBAHASAN}

Rumah Sakit Islam (RSI) Fatimah Banyuwangi merupakan salah satu rumah sakit swasta di Banyuwangi yang terletak di Jalan Jember Nomor 25, Banyuwangi, Jawa Timur, Indonesia. Sejarah terbentuknya RSI Fatimah Banyuwangi dimulai pada 01 Agustus 1984. Pimpinan Daerah Muhammadiyah Banyuwangi membentuk Panitia Pendirian Poliklinik Muhammadiyah yang diketuai oleh Bapak Humaidi. Sejak saat itu, panitia sering mengadakan pertemuan rutin sambil mengumpulkan dana dari masyarakat. Setelah terkumpul uang sumbangan sebesar lima belas juta rupiah, dana tersebut digunakan untuk membangun poliklinik yang menjadi cikal bakal rumah sakit ini. Selama dua tahun pembangunan dilaksanakan, hingga tahun 1986 poliklinik mulai dibuka untuk umum pada 01 September 1987.

Poliklinik Fatimah pada awal pengoperasiannya dipimpin oleh $\mathrm{dr}$. Soemarsono Qomar, Sp.OG, dibantu oleh dr. Abdul Hadi, Bidan Maslikanah, asisten apoteker Siti Nur Farida, Sulam Ismiyati, Titin Purnawati dan Huriyati Hamidah. Pada awalnya, Ibu Hj. Zulaikhah akan diabadikan sebagai nama rumah sakit. Beliau adalah pemberi wakaf tanah yang ditempati oleh rumah sakit. Namun akhirnya dipilih nama Fatimah (cucu Rasulullah SAW) sebagai nama rumah sakit karena nama tersebut dianggap paling cocok bagi rumah sakit yang akan didirikan itu.

Poliklinik-poliklinik tersebut berkembang menjadi rumah sakit sehingga pada akhirnya dibangun gedung untuk ruang rawat inap shofa, marwah, laboratorium dan radiologi. Pada 01 Oktober 1988 Rumah Sakit Islam Fatimah Banyuwangi resmi dibuka oleh Bupati Banyuwangi, Harwin Wasisto.
Visi dari Rumah Sakit Islam Fatimah yaitu menjadi rumah sakit dengan pelayanan prima sebagai sarana dakwah. Upaya yang dilakukan untuk mewujudkan visi tersebut antara lain memberikan pelayanan kesehatan yang bermutu, meningkatkan kesejahteraan sumber daya manusia dan menjadikan rumah sakit sebagai organisasi yang efektif dan efisien. Selain visi, rumah sakit ini juga memiliki tujuan. Tujuan dari rumah sakit ini yaitu terwujudnya pelayanan kesehatan yang bermutu, terlaksananya standar pelayanan rumah sakit, terwujudnya pengelolaan organisasi yang efektif dan efisien, terwujudnya pendayagunaan dan peningkatan sumber daya manusia, terwujudnya pendayagunaan dan peningkatan sumber daya manusia, serta terwujudnya fungsi rumah sakit sebagai sarana dakwah.

Hasil dari observasi promosi kesehatan di Rumah Sakit Islam Fatimah ini menggunakan instrumen observasi dan dikembangkan atau diperjelas dengan wawancara menggunakan panduan wawancara untuk mendeskripsikan kegiatan PKRS yang telah dilakukan oleh Rumah Sakit Fatimah Banyuwangi.

PKRS di Rumah Sakit Islam Fatimah mulai diadakan pada akhir 2017 dalam rangka kepentingan akreditasi. Unit dari PKRS di RSI Fatimah merupakan gabungan dari humas dan marketing. Pada dasarnya pelaksanaan promosi kesehatan di Rumah Sakit Islam Fatimah terdiri dari dua, yaitu promosi kesehatan di dalam gedung dan di luar gedung. Bentuk promosi kesehatan di dalam gedung terdapat dua jenis antara lain promosi kesehatan perorangan berupa KIE kepada pasien rawat jalan maupun rawat inap dan promosi kesehatan kelompok berupa penyuluhan kesehatan kepada keluarga pasien yang dilakukan secara terjadwal. Sedangkan bentuk promosi kesehatan di luar gedung misalnya berupa penyediaan 
baliho, brosur, leaflet, himbauan dan peringatan hari kesehatan.

Hasil observasi pelaksanaan PKRS

di Rumah Sakit Islam Fatimah Banyuwangi, antara lain :

\section{Kebijakan Manajemen Rumah Sakit Islam Fatimah}

Rumah Sakit Islam Fatimah memiliki unit PKRS yang merupakan gabungan dari humas dan marketing yang diketuai oleh Suprapto, SE. S.Kep. Ns. Kebijakan manajemen meliputi PKRS tersebut dapat dijalankan. Pelaksanaan kebijakan PKRS di RSI Fatimah didasarkan pada beberapa Undang-Undang, antara lain Peraturan Menteri Kesehatan RI Nomor 004 Tahun 2012 Tentang Petunjuk Teknis PKRS. Berdasarkan wawancara yang dilakukan, RSI Fatimah telah memilki kebijakan manajemen dalam menjalankan PKRS. Struktur organisasi PKRS juga diatur dalam SK Rumah Sakit. Petugas PKRS terdiri dari beberapa profesi seperti dokter, perawat, bidan, farmasi, gizi. Rumah sakit juga mampu memberikan sosialisasi kepada seluruh pengurus rumah sakit mengenai pelaksanaan PKRS.

\section{Kajian Kebutuhan Masyarakat Rumah Sakit Islam Fatimah}

Rumah Sakit Islam Fatimah memberikan fasilitas untuk memenuhi kebutuhan masyarakat rumah sakit, baik untuk pasien, keluarga pasien, maupun pengunjung rumah sakit. Berdasarkan rujukan yang peneliti gunakan, terdapat tiga indikator yang diambil dengan menggunakan metode observasi dan wawancara, antara lain : rumah sakit memiliki instrumen kajian kebutuhan informasi pasien, keluarga pasien, pengunjung rumah sakit, masyarakat sekitar serta memberikan media komunikasi yang sesuai; rumah sakit melakukan kajian kebutuhan informasi pasien, keluarga pasien, pengunjung rumah sakit, masyarakat sekitar serta media komunikasi yang sesuai; rumah sakit memiliki rumusan informasi yang dibutuhkan pasien, keluarga pasien, pengunjung rumah sakit, masyarakat sekitar rumah sakit serta media komunikasi yang sesuai. Rumah sakit mengadakan survey kepuasan yang instrumennya diletakkan di ruang tunggu dan ruang pelayanan untuk mendapatkan kebutuhan pasien, keluarga pasien dan pengunjung rumah sakit. Survey tersebut juga digunakan sebagai bahan evaluasi RSI Fatimah dalam melakukan perbaikan, terutama untuk pelaksanaan PKRS.

\section{Pemberdayaan Masyarakat Rumah Sakit Islam Fatimah}

Secara keseluruhan Rumah Sakit Islam Fatimah sangat memperhatikan upaya penyuluhan kepada pasien maupun masyarakat yang berada di lingkungan rumah sakit. RSI Fatimah telah memberikan informasi yang dibutuhkan pasien terkait dengan kondisi, pengobatan, perawatan serta faktor lain yang dapat mempengaruhi kondisi pasien baik melalui komunikasi secara langsung setelah pasien diperiksa maupun melalui media seperti poster, leaflet, dan lain sebagainya. Sedangkan penyuluhan kepada masyarakat yang berada di lingkungan rumah sakit, baik keluarga pasien maupun pengunjung lain dilakukan secara rutin setiap minggu hingga setiap bulan sekali. Penyuluhan kepada masyarakat yang berada di lingkungan rumah sakit yaitu berupa pengertian terkait penyakit, gejala penyakit dan bentuk pencegahan yang harus dilakukan. Upaya ini dilakukan rumah sakit dalam memampukan masyarakat lingkungan rumah sakit untuk dapat menjaga diri serta orang di sekitarnya agar mendapatkan derajat kesehatan yang setinggi-tingginya. Rumah sakit juga aktif memberikan penyuluhan kepada masyarakat di luar rumah sakit bila mendapatkan undangan atau sebagainya, 
hanya saja rumah sakit belum membentuk kelompok sehat tertentu pada masyarakat umum. RSI Fatimah juga menempelkan poster PHBS di dinding dan lokasi strategis, misalnya seperti langkahlangkah cuci tangan, larangan membuang sampah sembarangan, larangan merokok di area rumah sakit, etika batuk dan bersin, lima momen kebersihan tangan dan lainlain. RSI Fatimah memudahkan pasien maupun pengunjung lain dalam mendapatkan atau mengakses informasi kesehatan sesuai kebutuhan. RSI Fatimah juga menyediakan mading PKRS yang berada di ruang depan sebelum pengunjung memasuki area rawat inap.

\section{Rumah Sakit Melakukan Bina Suasana}

Rumah Sakit Islam Fatimah memanfaatkan ruangan dan halaman rumah sakit untuk memasang media dalam rangka upaya promosi kesehatan yang terdiri atas media visual maupun audio visual. Media visual, misalnya posterposter yang menjelaskan tentang pola hidup bersih dan sehat (PHBS) serta masalah penyakit. Selain dalam bentuk poster, media promosi kesehatan juga berupa brosur, leaflet, baliho, dan himbauan-himbauan. Sedangkan media audio visual yang ditayangkan yakni mengenai rumah sakit serta pelayanan yang dilaksanakan di rumah sakit. Tidak hanya itu, media audio visual juga menayangkan iklan kesehatan yang dapat bermanfaat bagi pengunjung rumah sakit. Rumah sakit Islam Fatimah juga memanfaatkan media massa untuk melakukan bina suasana sebagai upaya mendukung kegiatan pemberdayaan. Media massa yang digunakan oleh rumah sakit yaitu Radar Banyuwangi sebagai surat kabar harian (koran) yang ada di Banyuwangi. Selain surat kabar harian, rumah sakit juga memanfaatkan VIS FM sebagai stasiun radio yang ada di
Banyuwangi untuk menyiarkan informasiinformasi kesehatan. Siaran tersebut dilaksanakan rutin setiap satu minggu sekali, tepatnya di hari Rabu. Pihak rumah sakit juga melakukan talkshow menggunakan stasiun radio ini sebagai medianya. Media-media tersebut adalah sebuah upaya untuk menyampaikan materi atau pesan-pesan kesehatan (edukasi) kepada pasien, keluarga pasien, pengunjung dan masyarakat sekitar rumah sakit dalam pencegahan penyakit.

\section{Kemitraan}

Upaya yang dilakukan dalam rangka pelaksanaan promosi kesehatan di rumah sakit, pihak rumah sakit menjalin kemitraan dengan sektor lain, misalnya Kementerian Agama (KEMENAG). Salah satu program kerja dari Rumah Sakit Islam Fatimah yaitu bimbingan rohani kepada pasien, mengingat kesehatan tidak hanya sehat secara fisik, mental dan sosial melainkan juga sehat spiritual. Rumah sakit bekerja sama dengan KEMENAG dalam menjalankan program tersebut dengan mendatangkan petugas yang akan menyampaikan materi seputar spiritual yang tidak hanya untuk pasien yang beragama Islam tetapi juga ditujukan kepada pasien non Islam.

\section{Rumah Sakit Mewujudkan Tempat Kerja Sehat}

Promosi kesehatan yang dilaksanakan di Rumah Sakit Islam Fatimah tidak terlepas dari upaya pihak rumah sakit untuk mewujudkan tempat kerja sehat. Rumah sakit menjamin terjaganya keamanan ditandai dengan adanya petugas keamanan yaitu satpam yang selalu menjaga di pos satpam dan di pintu masuk lorong rumah sakit. Upaya dalam hal terjaminnya kebersihan lingkungan rumah sakit, pihak rumah sakit juga memiliki petugas kebersihan yang setiap hari membersihkan lingkungan 
rumah sakit, mulai dari ruang pendaftaran, taman yang ada di rumah sakit, ruang rawat inap, kantor pegawai maupun kamar mandi di rumah sakit sehingga lantai tidak kotor dan tidak licin. Kamar mandi yang terdapat di rumah sakit memiliki rincian antara lain lantai bersih, dan tidak licin, kloset tidak kotor dan tidak berbau, wangi, air bersih dan mengalir serta tersedia sabun. Upaya dalam mendukung kebersihan lingkungan rumah sakit, pihak rumah sakit menyediakan tempat sampah yang dibedakan berdasarkan jenis sampahnya yang diletakkan baik di dalam setiap ruangan maupun di luar ruangan. Rumah Sakit Islam Fatimah merupakan pelayanan kesehatan yang bebas dari rokok maupun asap rokok dibuktikan dengan adanya poster larangan merokok dibeberapa lokasi yang strategis. Upaya rumah sakit dalam mewujudkan tempat kerja yang sehat juga dibuktikan dengan adanya kegiatan yang dapat mengembangkan kesadaran untuk berperilaku hidup sehat, misalnya kerohanian, olahraga dan lain-lain.

\section{Promosi Kesehatan Dalam Gedung} Rumah Sakit Islam (RSI) Fatimah Banyuwangi melaksanakan beberapa kegiatan dalam upaya promosi kesehatan, yang dibuat dalam bentuk visual maupun audiovisual. Rumah sakit menyambut pasien dengan ramah saat pasien pertama kali masuk ke ruang pendaftaran. Pelaksanaan PKRS di dalam gedung antara lain ruang pendaftaran, pelayanan rawat jalan, pelayanan rawat inap, pelayanan penunjang medik, pelayanan rontgen, pelayanan obat/apotik, tempat pemulasaran jenazah, pelayanan bagi klien (orang sehat), dan di ruang pembayaran rawat inap.

a. Ruang Pendaftaran : Terdapat poster atau spanduk terkait dengan masalah kesehatan yang berganti setiap bulan sesuai dengan arahan dari tim PKRS.
Tersedia alur pelayanan di rumah sakit serta terdapat petugas yang menerima pengunjung rumah sakit. Tersedia informasi fasilitas pelayanan yang tersedia di rumah sakit, serta dokter ahli yang melayani di setiap poli dan jam pelayanan pada poli-poli tertentu.

b. Pelayanan Rawat Jalan : Upaya promosi kesehatan yang dilakukan di pelayanan rawat jalan tidak hanya dalam bentuk media saja, namun juga melakukan konseling pada pasien rawat jalan yang menderita penyakit tidak menular yang dilakukan pada saat pasien masuk untuk dirawat. Pasien diberikan pengetahuan terkait dengan penyakit yang diderita, intervensi yang harus dilakukan dan akan dilakukan, serta tindakan pencegahan agar tidak terkena penyakit tersebut. Selain kepada orang yang sakit, konseling juga dilakukan pada pasien rawat jalan yang sehat serta keluarga pasien. Pelayanan tersebut dilakukan dalam bentuk pelayanan $\mathrm{KB}$, konseling gizi, penyuluhan kepada keluarga pasien, motivasi dan bimbingan rohani setiap minggunya (hari Rabu). Sementara media yang ada di pelayanan rawat jalan adalah poster terkait dengan masalah kesehatan, seperti poster bahaya merokok, langkah-langkah CTPS, etika batuk dan bersin, penggunaan APAR, dan informasi terkait pemilahan sampah. Selain itu ada pula media audiovisual yang ditampilkan pada TV. Pesan yang disampaikan dalam media audiovisual tersebut berupa fasilitas dan pelayanan rumah sakit, dan beberapa isu kesehatan. Pemutaran video tersebut dilakukan setiap pagi hari, selama sekitar 1 jam.

c. Pelayanan Rawat Inap : Media yang terdapat di pelayanan rawat inap 
berupa leaflet yang disediakan untuk diambil oleh pengunjung RS (pasien, klien, keluarga pasien, dll), dan posterposter terkait masalah kesehatan sesuai dengan pembagian kelas dan ruangan layanan rawat inap. Contohnya di ruangan bayi dan anak, poster yang ditampilkan terkait dengan ASI, kehamilan, gizi anak, dll. Terdapat layanan konseling di tempat tidur yang dilakukan terhadap pasien yang belum dapat meninggalkan tempat tidur. Tersedia fasilitas biblioterapi sebagai sarana untuk membantu proses penyembuhan penyakit pasien. Fasilitas tersebut dibuat berupa pojok baca yang berisi koran dan leaflet.

d. Pelayanan Penunjang Medis : Promosi kesehatan dilakukan di laboratorium, baik kepada pasien, keluarga pasien, dan disediakan leaflet yang dapat diambil secara gratis di laboratorium.

e. Pelayanan Rontgen : Promosi kesehatan dilakukan di ruang rontgen, baik kepada pasien, keluarga pasien, dan disediakan leaflet yang dapat diambil secara gratis di ruang rontgen.

f. Pelayanan Obat/Apotik : Promosi kesehatan di pelayanan obat/apotik dilakukan saat pasien mengambil obat. Selain menjelaskan informasi konsumsi obat, petugas juga memberikan informasi preventif tentang penyakit yang diderita, berupa arahan dan nasehat.

g. Pelayanan Pemulasaraan Jenazah : Ruang jenazah di Rumah Sakit Islam Fatimah tidak diperuntukan untuk otopsi maupun penyimpanan jenazah dengan jangka waktu lama. Tidak terdapat media promosi kesehatan secara khusus di ruang jenazah namun hanya pemberitahuan pemakaian sepatu dan himbauan cuci tangan. Terdapat pula pesan keagamaan di pintu masuk ruang pemulasaraan jenazah.

h. Pelayanan Bagi Klien (Orang Sehat) : Setiap petugas pelayanan wajib memberikan konseling kepada pengunjung rumah sakit yang hanya mengantarkan pasien untuk upaya promotif dan preventif, misalnya konseling gizi.

i. Ruang Pembayaran Rawat Inap : Promosi kesehatan yang dilakukan berupa nasehat untuk kesehatan pasien yang diberikan kepada pasien itu sendiri maupun keluarganya sebelum meninggalkan rumah sakit. Petugas juga memberikan motivasi kepada pasien dengan tujuan agar lekas sembuh.

\section{Promosi Kesehatan Luar Gedung}

Pelaksanaan promosi kesehatan di luar gedung pada RSI Fatimah dapat dilihat pelaksanaannya pada tempat parkir, di taman rumah sakit, pada dinding luar rumah sakit, di kantin atau warung rumah sakit, tempat ibadah, dan di pagar pembatas kawasan rumah sakit. Promosi kesehatan di luar gedung rumah sakit dilakukan dengan menempatkan mediamedia visual seperti poster larangan merokok dan informasi pemilahan sampah di tempat parkir, kantin, serta taman, banner yang dipasang di dinding luar dan pagar pembatas kawasan rumah sakit.

\section{Advokasi}

Kegiatan advokasi yang dilakukan untuk mendukung upaya promosi kesehatan rumah sakit adalah penerapan kebijakan kawasan tanpa rokok di area rumah sakit. Hal tersebut dibuktikan dengan terpasangnya poster/spanduk kawasan tanpa rokok di area rumah sakit. 


\section{SIMPULAN DAN SARAN}

Promosi kesehatan yang dilakukan di Rumah Sakit Islam Fatimah secara keseluruhan telah memenuhi persyaratan undang-undang. Hal ini juga didukung sertifikasi rumah sakit terhadap pelayanan PKRS. Mulai dari manajemen kebijakan hingga pelaksanaan disusun dengan baik dan terarah. Pembagian petugas PKRS terdiri dari berbagai bidang, seperti dokter, perawat, petugas gizi dan pelayanan kesehatan lain untuk mempermudah dalam radikalisasi informasi promosi kesehatan. Pelayanan di setiap bidang hampir terdapat pemberian informasi secara visual leaflet, poster maupun papan informasi.

Rumah sakit Fatimah ini juga aktif dalam memberikan penyuluhan kepada pasien, keluarga pasien dan petugas kesehatan lain dalam upaya peningkatan pengetahuan terhadap masalah kesehatan tertentu setiap minggu sekali, serta bimbingan rohani kepada pasien rawat inap. Poin lebih dari Rumah Sakit Islam Fatimah Banyuwangi ini yaitu pemberian informasi kepada masyarakat melalui media sosial (facebook, instagram). Selain itu, pihak rumah sakit juga bekerja sama dan menjalin kemitraan dengan media massa berupa surat kabar harian (koran) dan stasiun radio. Pemenuhan kebutuhan promosi kesehatan secara umum telah dilaksanakan dengan baik, akan tetapi pada poin pemberian informasi kepada masyarakat sekitar terlihat tidak intens dan belum membentuk kelompok kesehatan tertentu guna pemberdayaan masyarakat. Pihak rumah sakit menyediakan kotak saran yang dapat dijadikan sebagai dasar instrumen kepuasan pengunjung rumah sakit. Instrumen kepuasan tersebut terdiri dari pilihan "puas" atau "tidak puas" serta kolom komentar atau saran.
Tim PKRS Rumah Sakit Islam Fatimah perlu menyediakan media-media khusus terkait metode penanganan pasien kepada petugas medis, karena promosi kesehatan di rumah sakit juga ditujukan kepada petugas kesehatan, misalnya seperti cara penggunaan alat di bagian radiologi, walaupun petugas telah memahami tugas dan fungsinya, hal tersebut dilakukan sebagai upaya promosi kesehatan kepada petugas untuk pengurangan risiko terhadap terjadinya kesalahan dan kecelakaan.

\section{DAFTAR RUJUKAN}

[1] Bastian, I. 2014. Modul 1 : Paradigma Baru Manajemen Kesehatan. Repository Universitas Terbuka

[2] Departemen Kesehatan RI. 2009. SIMTEM KESEHATAN NASIONAL Jakarta: Republik Indonsesia

[3] Health Promotion Hospital Organitation. 2001. News Letter : $9^{\text {th }}$ International Conference on Health Promotion Hospitals. Copenhagen

[4] Kementerian Kesehatan RI. 2011. "Promosi Kesehatan Di Daerah Bermasalah Kesehatan". Jakarta: Kementerian Kesehatan RI Pusat Promosi Kesehatan.

[5] Menteri Kesehatan RI. 2006. "Keputusan Menteri Kesehatan Republik Indonesia Tentang Petunjuk Teknis Promosi Kesehatan Rumah Sakit".

[6] Menteri Kesehatan RI. 2012. "Peraturan Menteri Kesehatan Nomor 004 Tahun 2012 Tentang Petunjuk Teknis Promosi Kesehatan Rumah Sakit" Jakarta.

[7] Notoatmodjo, S. 2007. Promosi Kesehatan: Teori dan Aplikasi. Jakarta:Rineka cipta 
[8] Peraturan Menteri Kesehatan Republik Indonesia Nomor 004 Tahun 2012 Tentang Petunjuk Teknis Promosi Kesehatan Rumah Sakit. Jakarta: Kemenkes

[9] Pusat Promosi Kesehatan. 2011. "Kementerian Kesehatan Republik Indonesia Tahun 2011 Tentang Standar Promosi Kesehatan Rumah Sakit (PKRS)".

[10] Pusat Promosi Kesehatan. 2013. "Kementerian Kesehatan RI Tahun 2013". Tentang Standar Promosi Kesehatan Rumah Sakit (PKRS)".

[11] Undang-Undang Republik Indonesia Nomor 36 Tahun 2009 Tentang Kesehatan. Jakarta: Republik Indonesia.

[12] WHO. 2004. "Standards for Health Promotion In Hospitals".WHO Regional Office for Europe.

[13] World Health Organization. 2003. "Standards for Health Promotion in Hospitals : Development of Indicators for a Self-Assessment Tool". Report on $4^{\text {th }}$ WHO Workshop. Barcelona, Spain. 